\title{
When an Oncology Specialist's Parent has Metastatic Cancer
}

\author{
Lillie D Shockney* \\ Department of Surgery and Oncology, Johns Hopkins Breast Center, USA
}

Received: February 18, 2014; Accepted: February 19, 2014; Published: February 21, 2014

*Corresponding author: Lillie D Shockney, Department of Surgery and Oncology, The Johns Hopkins Breast Center, $600 \mathrm{~N}$ Wolfe Street, Carnegie, Room 683, Baltimore, MD 21287, USA, Tel: 410-614-2853; Fax: 443-873-5014; E-mail: shockli@jhmi.edu

\section{Editorial}

Though we all know the statistics associated with the incidence of cancer, and expect to personally know friends and family members who end up diagnosed with some form of cancer, it can strike hard on the psyche when it ends up being one of your parents diagnosed with metastatic disease. I have faced that situation and recently buried my father less than a month ago. Though there are many patients that stick out in my mind for various and specific reasons, this patient I will of course remember forever. My goal for him was to help ensure he experienced a good death. And he did.

Family dynamics play out differently when the clinician directly involved in the patient's care and decision making is a close family member. There were many times over the last 5 years that I have needed to be two people, alternating moment to moment from one role to the other - the oncology clinician and the daughter whose father is dying. I witnessed firsthand the struggle my mother had when it was time to discontinue treatment. She still wanted him to have his cholesterol medicine each day and couldn't understand why it was no longer needed or important. I would go from sitting at his bedside as a clinician, asking him about his pain level to ensure he was as pain free as possible, taking his pulse, checking his foley catheter, then one minute later resuming the role of daughter who wanted to just be present and do nothing medically related.

His affairs were in order, he knew his purpose in life (being the patriarch for farmers on the Eastern Shore of Maryland), dignity preserved, no pain, specific family he did want (and didn't want) at his bedside or even at his funeral. He left several legacies, he left no financial debt for my mother associated with his cancer treatment, and he knew he would be spoken of kindly by others after he was gone. All important ingredients to creating a good death. He even planned his own funeral which was a grave side service lasting only ten minutes and specified that he wanted to be buried on a Saturday as to no negatively impact the work schedules of immediate family who would be present. He wrote his own obituary. He wanted control regarding everything that he possibly could control given he could not control his time remaining on this earth.

I know of other patients however who did not experience a good death. They received chemotherapy within a couple of weeks of their life ending. Families were unprepared and emotionally shattered and for many months and possibly years will still be wondering what happened and why did their loved one have to die "this way", without the opportunity to experience a good death which they deserved.

We don't see these families after our patients have died. I think we should however. Not just in the immediate sense when the patient dies in the hospital and you are there consoling the family for a few minutes. What I am referring to is seeing the family several months later, and again around the one year anniversary to see how they are doing. If we had a formal meeting with them or at least a window into their world we would all learn a lot. Though our responsibilities we believe may be "done" in our minds, the grieving family members continue to struggle with loss, with medical bills, with trying to figure out why their loved one suffered, and why there was no time to properly prepare and plan for him leaving them.

So as I am now grieving and becoming ever so aware of the hole in my heart, and that the absence of my dad's voice is deafening, I am learning more lessons as a clinician so that I can further ensure more patients experience a good death and as part of that process family members are prepared and take part in orchestrating a good death with me on behalf of their loved one who is dying. I want to always be able to look back and reminisce with a smile that all that could be done to ensure the patient was ready, family was ready, wishes honored, pain relieved, dignity maintained, purpose in life known and admired, as well as the patient's personal goals achieved have been fulfilled. In doing so, we as oncology specialists are given the privilege to share in this fulfillment. No tears. Just a smile. 